VII JORNADAS DE DIFUSIÓN DE LA INVESTIGACIÓN Y EXTENSIÓN - FCV-UNL

RESUMEN EXTENDIDO

\title{
DILUCIÓN DE MIEL EN AGUA INDUCE HORMESIS EN LA ACTIVIDAD ANTIBACTERIANA SOBRE Staphylococcus aureus.
}

\author{
Castromán $\mathrm{R}^{1}$, Dell'Elce $\mathrm{A}^{1}$, Ferrer $\mathrm{A}^{1}$, Menseguéz $\mathrm{S}^{1}$, Anadón $\mathrm{A}^{1}$, Candioti V2, \\ Picco E1, Formentini E1. \\ ${ }^{1}$ Laboratorio de Farmacología y Toxicología, FCV-UNL \\ ${ }^{2}$ Cátedra de Semiología, FCV-UNL \\ * Correspondencia: Castromán R. E-mail: castromanrocio12@gmail.com
}

Editado por: R. Sobrero, V. Matiller, C. Baravalle.

THE DILUTION OF HONEY IN WATER INDUCES HORMESIS ON ITS ANTIBACTERIAL ACTIVITY AGAINST Staphylococcus aureus.

\section{SUMMARY.}

In pharmacology, hormesis is defined as the high efficacy of a drug at low doses and a decrease of efficacy at higher doses. In this study, the hormesis phenomenon on the antibacterial activity of honey was assessed. The activity of four honeys (A, D, C and D) were checked by agar plate diffusion method using S. aureus (ATCC 29213) as the test organism. Each honey was tested as follows; on the surface of an agar plate, five stainless steel cylinders with a diameter of $8,14 \mathrm{~mm}$ were radially disposed. Onto each cylinder $0,1 \mathrm{~mL}$ of the sample honey diluted in water at $50-25-12,5-6,25$ and 3,125\% v/v were placed. Plates were incubated at $35^{\circ} \mathrm{C}$ during $24 \mathrm{~h}$. The surface of the cylinder diameter was set as reference antibacterial activity (Ra). The antibacterial activity of each honey was quantitated by the relationship between the surface of the inhibitory zone (Iz) and the surface of the reference activity (Iz/Ra). An increase in the antibacterial activity was observed at a concentration of water greater than $50 \%$ in honeys B and C. This hormetic behavior could be considered as indicator of the quality of the antibacterial activity of these honeys.

Palabras clave: Miel, Actividad antibacteriana, Staphylococcus aureus, Hormesis

Keywords: Honey, Antibacterial activity, Staphylococcus aureus, Hormesis

En farmacología se denomina hormesis a un aumento de eficacia a dosis bajas y a un descenso de la misma a dosis elevadas, resultando en una curva dosis respuesta en forma de " $\mathrm{J}$ " invertida. La actividad antibacteriana de la miel se atribuye a elevada osmolaridad, acidez, concentración peróxido y radicales no peróxidos como óxido nítrico y fenoles (Oryan et al., 2016). Aún se discute cual es la concentración de miel que presenta la mayor actividad antibacteriana. Muchas técnicas in vitro se han reportado para evaluar la actividad antibacteriana de la miel, sin embargo no hemos hallado en la literatura ningún método estandarizado para realizar comparaciones entre distintas mieles respecto de una actividad basal o de referencia. En este trabajo utilizamos una metodología desarrollada por nosotros para evaluar la actividad antibacteriana de diferentes concentraciones de miel. Se utilizó una cepa estandarizada de Staphylococcus aureus (S. aureus) y cuatro mieles que previamente habían mostrado actividad antibacteriana in vitro sobre $S$. aureus las que se presentan en la tabla 1.

Tabla 1. Caracterización de cuatro tipos de mieles que previamente habían presentado actividad antibacteriana sobre $S$. aureus. 


\begin{tabular}{ccccc}
\hline Identificación & Denominación & $\begin{array}{c}\text { Tipo de } \\
\text { miel }\end{array}$ & $\begin{array}{c}\text { Ciudad de } \\
\text { orígen }\end{array}$ & Prov. \\
\hline A & "Monacal" & Comercial & Victoria & Entre Ríos \\
B* & FCV-UNL & Productor & Esperanza & Santa Fe \\
C & "El Ocaso" & Productor & Esquina & Corrientes \\
D & "Don & Productor & San Martín & Santa Fe \\
& Francisco" & & & \\
\hline
\end{tabular}

(*) Miel producida por el Grupo Funcional Apícola de la FCV en el apiario de la Unidad Académico Productiva (UAP) de la FCVUNL.

A partir de un cultivo nuevo de $S$. aureus se preparó un inóculo $(0,5 \times 105 \mathrm{ufc} / \mathrm{mL})$ en solución fisiológica. Se inoculó agar Mueller Hinton esterilizado con $0,1 \mathrm{~mL}$ del inóculo cada $100 \mathrm{~mL}$ de agar. Se sembraron placas con agar hasta un espesor aproximado de $3 \mathrm{~mm}$. Sobre la superficie de cada placa se colocaron en disposición radial cinco cilindros de acero inoxidable de $8,14 \mathrm{~mm}$ de diámetro y $8,14 \mathrm{~mm}$ de altura. Para cada miel se utilizó una placa y en el interior de cada cilindro se colocó un volumen de 0,1 mL de miel al 50-25-12,5-6,25 y 3,125 $\% \mathrm{v} / \mathrm{v}$. El ensayo se realizó por triplicado. Las placas se colocaron en estufa a $35^{\circ} \mathrm{C}$ durante $24 \mathrm{~h}$. Posteriormente se retiraron los cilindros y se midió el diámetro del halo de inhibición (A) y el halo central (C) determinado por los bordes del cilindro de acero inoxidable. Considerando que el diámetro del halo de inhibición es originado por la migración de los factores con actividad antibacteriana a través de la fase acuosa del agar, se asumió que el límite entre la zona de inhibición y la zona de crecimiento (C) corresponde a la concentración inhibitoria mínima de la miel (CIMM). Como actividad de referencia se consideró un halo de inhibición equivalente el diámetro central del cilindro de acero inoxidable, asumiendo que esa es la menor actividad antibacteriana cuantificable tal como se presenta en la figura 1.

La cuantificación de la actividad antibacteriana de cada miel se determinó estableciendo la relación entre la superficie del halo central (Sc) y la superficie del halo de inhibición (Si) utilizando las ecuaciones 1 al 3.

$$
\begin{array}{cc}
S_{c}=\pi \cdot\left(r_{c}\right)^{2} \text { donde } r_{c}=\left(\emptyset H_{c}\right) / 2 & \text { Ecuación 1 } \\
S_{i}=\pi \cdot\left(r_{i}\right)^{2} \text { donde } r_{i}=\left(\emptyset H_{i}\right) / 2 & \text { Ecuación 2 } \\
\times C I M=S_{i} / S_{c} & \text { Ecuación 3 }
\end{array}
$$

Donde Sc y Si son las superficies $(\mathrm{mm} 2)$ del halo central y de inhibición respectivamente, rc y ri son los radios del halo central y de inhibición respectivamente, $\varnothing \mathrm{Hc}$ y $\varnothing \mathrm{Hi}$ son los diámetros del halo central y de inhibición.
La relación entre $\mathrm{Si}$ y Sc determina el valor de los múltiplos de la CIMM presentes en la Si

La actividad de las concentraciones sub-inhibitorias se determinó como \% de turbidez de la superficie del halo central. Los resultados de la actividad antibacteriana de las cuatro mieles expresadas como múltiplos de la actividad basal (x CIM) para cada dilución (\% de agua) se presentan en la figura 2.

En las mieles $A$ y $D$ se observó disminución de la actividad antibacteriana proporcional al incremento de la dilución (\% de agua), sin embargo, se observó un incremento de la actividad a una concentración de agua mayor al $50 \%$ en las mieles B y C. Nosotros proponemos que este efecto hormético o paradojal puede ser debido a que estas mieles pueden contener menor proporción de agua libre, la que es necesaria para la actividad de la enzima glucosa-oxidasa, que cataliza la reacción que produce ácido glucónico y peróxido de hidrógeno (Szeda, 2017) que es uno de los compuestos que se postula como el principal responsable de la actividad antibacteriana de la miel (Figura 3).

Como conclusión, hemos observado que la mayor actividad antibacteriana sobre $S$. aureus fue obtenida con la miel procedente de la Unidad Académico Productiva (UAP) de la FCV-UNL, y que esa actividad (2,44 x CIM) se obtuvo con una concentración $25 \%$ p/v de miel ( $75 \%$ de agua). Este comportamiento hormético en la actividad antibacteriana de esta miel puede ser considerado como un indicador de la calidad del producto producido en la UAP de la FCV-UNL.

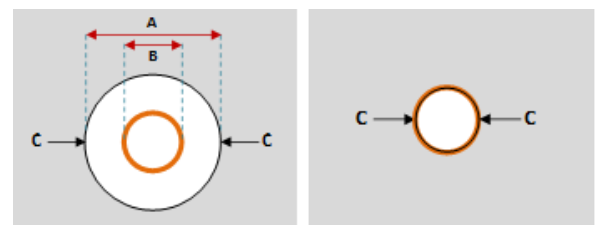

Figura 1. Representación gráfica de la actividad antibacteriana de miel determinada por la técnica del cilindro en placa; A y B son los diámetros del halo de inhibición y el halo central respectivamente y $C$ corresponde a la interfase equivalente a la concentración inhibitoria mínima de la miel.

La cuantificación de la actividad antibacteriana de cada miel se determinó estableciendo la relación entre la superficie del halo central (Sc) y la superficie del halo de inhibición (Si) utilizando las ecuaciones 1 al 3. 

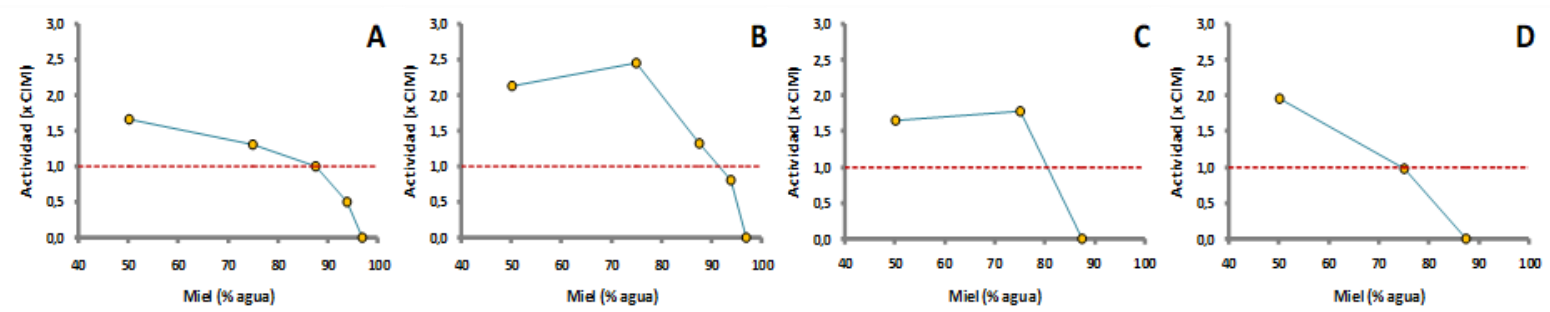

Figura 2. Actividad antibacteriana de cuatro mieles ( $A, B, C$ y $D)$ expresadas como múltiplos de la actividad basal $(x \mathrm{CIM})$ observados para cada dilución (50-25-12,5-6,25 y 3,125 \% v/v). La línea roja de puntos representa el valor o actividad basal representada como la unidad o $\mathrm{CIM}_{\mathrm{M}}$.

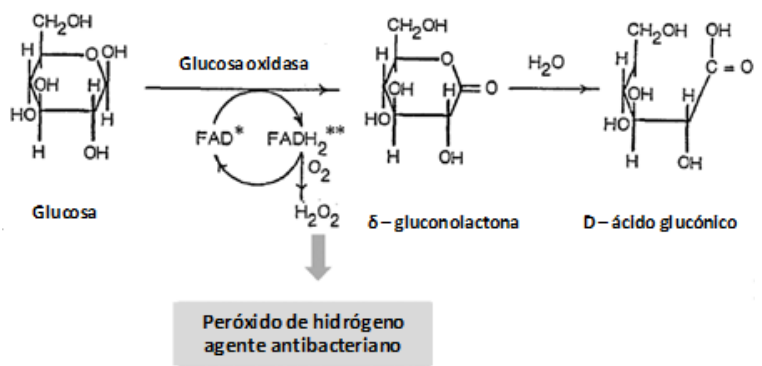

Figura 3. Representación esquemática de la reacción catalizada por la enzima glucosa oxidasa que da como producto final ácido glucónico (responsable del pH ácido de la miel) y de peróxido de hidrógeno, al cual se le considera como el principal compuesto con actividad antibacteriana de la miel.

\section{Bibliografía}

Oryan A, Alemzadeh E, Moshiri A. 2016. Biological properties and therapeutic activities of honey in wound healing: A narrative review and meta-analysis. J. Tissue Viability. 25(2): 98-118.

Szeda P. 2017. Antimicrobial activity of honey. IntechOpen. http://dx.doi.org/10.5772/67117. 